\title{
When Domestic Goes Capital: Juror Decision Making in Capital Murder Trials Involving Domestic Homicide
}

\author{
Tara N. Richards \\ University of Baltimore
}

\author{
M. Dwayne Smith and Sondra J. Fogel \\ University of South Florida
}

\author{
Beth Bjerregaard \\ University of North Carolina at Charlotte
}

\begin{abstract}
Prior research suggests that homicide cases involving familial offenders and victims are subject to a "domestic discount" that reduces sentencing severity. However, the operation of a domestic discount in regard to death penalty sentencing has been rarely examined. The current research uses a near-population of jury decisions in capital murder trials conducted in North Carolina from 1991 to 2009 ( $n=800)$, and a series of logistic regression analyses to determine whether there is (a) a direct effect between offender-victim relationship (e.g., domestic, friend/acquaintance, and stranger) and jury decision making, and/or (b) whether domestic offender-victim relationship (as well as other offender-victim relationships) moderates the effect of legal and extralegal case characteristics on jury assessment of the death penalty. Our findings revealed no empirical support for a "domestic discount" whereby juries are less likely to impose death sentences in cases involving domestic homicides. However, substantial differences in predictors of death sentencing were found across offender-victim dyads; most notably, domestic homicide cases demonstrated the most legalistic model of jury decisions to impose death sentences.
\end{abstract}

Keywords: death penalty, jury decision making, offender-victim relationship, domestic discount

Extant research demonstrates that the majority of homicides in the United States each year involve offenders and victims who know one another (Cooper \& Smith, 2011). At the same time, some evidence suggests that homicides between offenders and victims who are strangers receive the most severe punishments (Dawson, 2004). Prior literature provides evidence that this seeming disconnect may be explained, at least in part, by the application of a "domestic discount" (Rapaport, 1996) based on relational distance and corresponding perceptions regarding offender culpability and dangerousness. However, although some prior research demonstrates the application of less law in cases of domestic homicide compared with cases involving other offender-victim relationship dyads, a paucity of research has examined whether a domestic discount is in operation among capital cases. Further, there is a lack of research regarding what case characteristics serve as predictors of receiving the death penalty for the domestic homicides that are tried capitally, especially compared with cases

Tara N. Richards, School of Criminal Justice, University of Baltimore; M. Dwayne Smith, Department of Criminology, Office of the Provost, University of South Florida; Sondra J. Fogel, School of Social Work, Honors College, University of South Florida; Beth Bjerregaard, Department of Criminal Justice \& Criminology, University of North Carolina at Charlotte.

Correspondence concerning this article should be addressed to Tara N. Richards, School of Criminal Justice, University of Baltimore, 1420 North Charles Street, AC242B, Baltimore, MD 21201. E-mail: trichards@ubalt.edu with other offender-victim relationships. Addressing these limitations in the literature, the present study uses a near-population of capital cases from North Carolina to investigate both the direct effect and moderating effect of domestic offender-victim relationship on jury death penalty decision making, with comparisons of these cases with cases including other offender-victim relationships.

\section{Prior Research}

In the United States, the death penalty is typically reserved for only the most egregious crimes, especially that of aggravated homicide. Data reveal that of the approximately 15,000 homicides that occur in the United States each year only about 100 cases are sentenced to the death penalty (Snell, 2011). Of those receiving capital punishment, very few include cases of domestic homicide (Rapaport, 1996). At the same time, domestic homicides constitute a substantial portion of the homicides committed annually. From 1980 to 2008, among homicides for which the offender-victim relationship was known, more than two thirds of homicides involved offenders and victims known to one another (Cooper \& Smith, 2011). Further, in 2012, 93\% of all female homicide victims were killed by a man they knew, and $62 \%$ of these women were the wives or girlfriends of the offender (Violence Policy Center, 2014). Thus, the question remains, what does it take for a domestic homicide to receive the death penalty?

In her seminal piece on capital-sentencing decisions in cases of intimate partner homicide, Rapaport (1996) suggests that homicides between intimates are often subject to a "domestic discount" whereby the offender-victim relationship serves as an automatic mitigator and reduces the severity of charges and/or sentencing. 
The notion of a "domestic discount" stems from Black's (1976) theory of relational distance. Specifically, Black posited that the level of intimacy between victims and offenders directly affects the severity of the criminal justice system's response to crime-as the relational distance between victims and offenders increases, the criminal justice system responds more harshly. In the context of homicide, relational distance may impact the punishment of domestic homicides because of perceptions that domestic killers act on provocation by the victim and/or are motivated by strong emotions (e.g., crimes of passion; Hessick, 2007; Miethe, 1987; Rapaport, 1991, 1996). In addition, domestic killers may be viewed as less dangerous to society compared with "predatory" offenders who harm strangers (Hessick, 2007; Rapaport, 1996). Moreover victims who are killed by individuals they know may be seen as less sympathetic or credible, given that they spent time with the offender and may be held partially responsible for their own death (Hessick, 2007). Further, the presence of a "domestic discount" may be related to the nature of the criminal intent involved in domestic homicides. Domestic homicides may lack the level of criminal premeditation to warrant a more severe response by the criminal justice system (for a discussion, see Dawson, 2004; Hessick, 2007). Taken together, perceptions regarding reduced levels of premeditation and/or criminal intent, as well as victim provocation, may mitigate offender culpability for sentencing decision makers, such as judges and juries, and result in less severe criminal sanctions (Dawson, 2004; Hessick, 2007; Miethe, 1987; Rapaport, 1991).

Evidence regarding the use of a domestic discount in the punishment of intimate homicides has been inconsistent; however, studies that examine different stages of prosecution and sentencing have generally identified the role of offender-victim relationship as a mitigating factor in criminal justice system response to homicide. Auerhahn (2007), for instance, compared the bivariate relationship between offender-victim relationship, and the conviction offense (first-degree murder, second-degree murder, thirddegree murder, voluntary manslaughter, and involuntary manslaughter) for all intimate and nonintimate partner homicides in Philadelphia from 1995 to $2000(N=1,137)$. Her results provided mixed findings regarding the presence of a domestic discount, in that perpetrators of intimate partner homicides were significantly more likely to be sentenced to the least and most severe offense categories, manslaughter and first-degree murder, and correspondingly, to the least and most severe sentence types, probation and the death penalty, compared with perpetrators of nonintimate partner homicides.

In another study, Dawson (2012) examined a population of Canadian homicide cases processed through the Toronto adult criminal court between 1974 and $2002(N=1,043)$. Specifically, she investigated the impact of intimate partner relationship (vs. nonintimate partner relationship) on five dichotomous criminal justice outcomes: first-degree murder charge, case sent to trial, guilty verdict, conviction, first-degree murder conviction, and length of sentence, while controlling for a host of victim, offender, and case characteristics. Findings revealed evidence of a domestic discount in mode of prosecution - cases involving intimate partners were more likely to be resolved through plea bargaining rather than at trial. However, no domestic discount was found regarding the severity of charging and sentencing, findings of guilt, or the likelihood of a conviction. More specifically, cases including intimate partners that were sent to trial were more likely to be found guilty and were more likely to result in a conviction (either by plea bargain or at trial) than cases not involving intimate partners. No significant differences were observed between intimate-nonintimate partner cases regarding severity of conviction (murder vs. manslaughter).

Dawson (2004) provides the most nuanced investigation to date regarding the domestic discount in homicide sentencing by moving beyond the dichotomous categories of intimate and nonintimate victim-defendant relationships. She developed five relationship categories - "strangers, acquaintances, friends, family members (excluding spouses), and intimate partners" (p. 112)-in an attempt to capture any within-group differences based on the level of intimacy in the victim-defendant relationship. To do so, Dawson analyzed all homicide cases processed through the adult criminal court in Ontario, Canada, from 1974 to $1996(N=1,003)$. Specifically, Dawson regressed each relationship category (using strangers as the reference category) on four dichotomous criminal justice outcomes: first-degree murder charge, case sent to trial, guilty verdict and conviction, and length of sentence, and again controlled for victim, offender, and case characteristics. Dawson's findings identified a domestic discount regarding both charging and sentencing, whereby cases involving intimate partners were less likely to be charged with first-degree murder or sent to trial compared with cases involving strangers. Conversely, cases including two other types of offender-victim dyads usually considered "intimates" - family and friends - were treated no differently than strangers. Likewise, a domestic discount was identified regarding length of sentence-cases involving intimate partners received sentences that were about 1 year shorter than cases including strangers; cases including family members received sentences that were almost 2[1/2] years shorter than cases including strangers, whereas cases including friends/acquaintances received sentences that were no different than cases including strangers.

Additionally, three studies to date have specifically examined the domestic discount in capital punishment decision making. To begin with, Rapaport (1996) provides an examination of case characteristics of domestic homicides for which defendants had been sentenced to the death penalty. In her study, she performed a qualitative analysis of all cases of women sentenced to death for killing an intimate from 1978 to $1989(n=26)$ and all men sentenced to death for killing an intimate in six states from 1979 to 1991 ( $n=83$ ) whose cases had been subjected to appellate review to investigate the characteristics of domestic homicides that resulted in the death penalty. As part of her analysis, Rapaport stratified cases by motivation: retaliatory, pecuniary, and other. She found that the majority of female domestic killers who had been sentenced to death were motivated by pecuniary gain, whereas the majority of male domestic killers had committed the murder out of retaliation, oftentimes because the victim had been unfaithful or had left the perpetrator. Rapaport also identified four important aggravating factors in male perpetrated domestic killings: extreme brutality (heinous and cruel), commission of the murder in the course of another felony, multiple victims, and a prior record of violence by the perpetrator. Comparatively, in the overwhelming majority of female perpetrated cases murder for pecuniary gain was the aggravating factor that was most often present in the case. 
In another study focusing on domestic homicide, Messing and Heeren (2009) generated a national sample of murder cases through searches of newspaper databases in which individuals had killed multiple victims who were intimate partners, family members, associates or family members of the intimate partner, or strangers caught up in the homicidal incident. Their purpose was to determine whether differential treatment was evident for those cases with male $(n=51)$ versus female $(n=18)$ perpetrators. Overall, they found the relative proportions of male and female defendants for whom the death penalty was sought, and for whom a death penalty was assessed by a jury, were similar. However, it appeared that greater leniency was shown for males who murdered children, especially when firearms were used in commission of the crimes. In addition, males who murdered intimate partners who had separated from them were less likely than female perpetrators to receive the death penalty, a finding Messing and Heeren believe lends support to Rapaport's (1996) notion of a domestic discount in homicide cases.

Finally, Grosso, Baldus, and Woodworth (2010) provide the sole quantitative test of the domestic discount in capital punishment decision making. Using data on death-eligible homicides prosecuted under the U.S. Armed Forces capital punishment system from 1984 to 2005 ( $N=104)$, Grosso et al. examined whether cases including intimate partners (former or current intimate partners; $n=25$ ) were less likely to result in three dichotomous criminal justice outcomes - court martial, advancement to a capital sentencing hearing, and a death sentence - than cases including nondomestic homicides $(n=79)$. Bivariate findings indicated that domestic homicides were less likely to be advanced to the capital (court martial) phase (32\% vs. $46 \%$ ), advanced to a capital sentencing hearing ( $22 \%$ vs. $34 \%)$, and sentenced to death $(20 \%$ vs. $56 \%$ ) when compared with cases not involving intimate partners. However, none of these differences were statistically significant. Additional multivariate analyses that included controls for the number of aggravating factors, each aggravating factor individually, and whether the victim was White were also estimated for each of the charging and sentencing stages. Findings indicated that domestic homicide cases were less likely to be sentenced to death compared with nondomestic homicides; again, however, the differences were not statistically significant. Nonetheless, Grosso et al. suggest that their findings represent evidence regarding the presence of a domestic discount and argue that their small sample size likely impacted the significance of their estimates.

Taken together, although Rapaport's (1996) seminal study is instructive, it does not test whether a domestic discount actually exists in the sentencing of domestic homicides. Messing and Heeren (2009) do provide some comparison regarding the sentencing of domestic or intimate homicides versus homicides involving other defendant-victim relationship dyads via what they admit is a very limited sample of cases; however, their study, like Rapaport's, does not address whether there are characteristics of domestic homicide cases that distinguish them from homicides with other offender-victim combinations. In addition, neither study considers the potential confounding impacts of numerous control variables that have proved important in previous investigations regarding death penalty sentence decision making (Baldus \& Woodworth, 2003; Kavanaugh-Earl, Cochran, Smith, Fogel, \& Bjerregaard, 2008). In particular, several individual aggravators, including victim rape and the jury's acceptance that the murder was heinous and cruel, may impact sentencing decisions above and beyond the presence of other aggravators (Richards et al., 2014). Although Grosso et al. (2010) did include a number of aggravators and individual aggravators in their analysis, the small sample size and rarity of the death penalty in the data $(n=25)$ limited their analysis. In addition, previous studies have found extralegal variables, such as victim sex (Holcomb, Williams, \& Demuth, 2004; Richards et al., 2014; Williams \& Holcomb, 2004), victim and defendant race (Baldus \& Woodworth, 2003; Holcomb et al., 2004; Kavanaugh-Earl et al., 2008; Williams \& Holcomb, 2004), victim and defendant age (Richards et al., 2014), and victim illegal activity (Gillespie, Loughran, Smith, Fogel, \& Bjerregaard, 2014; Stauffer, Smith, Cochran, Fogel, \& Bjerregaard, 2006), to be related to death penalty sentencing. Various factors involved in mitigation presented by defense teams may also sway jury decisions (Bjerregaard, Smith, Fogel, \& Palacios, 2010; Kremling, Smith, Cochran, Bjerregaard, \& Fogel, 2007) in assessing a life sentence instead of the death penalty.

Prior research on the context of homicide generally, and capital sentencing specifically, provides evidence that some confounding variables may play a more significant role in capital trials across the different offender-victim relationship groups. For example, the role of aggravating factors may be more significant in stranger murders that often take place during the course of another crime(s), whereas the victim being involved in illegal activity may be important in cases of friends/acquaintances, in which mutual illegal activity might have ended in the homicide. Comparatively, mitigation may be a more important factor in domestic cases that include a defendant and victim that have an emotional and/or physical relationship and may share common living space. Notably, prior research demonstrates that female homicide victims are most often killed by a man known to them (Violence Policy Center, 2014), and the majority of child victims are killed by a family member (Cooper \& Smith, 2011). Further, domestic relationships, and to a lesser extent, homicides between friends/acquaintances, are likely to be intraracial versus interracial. This may be important because the literature examining racial threat/conflict theory notes that interracial stranger crimes, especially those perpetrated by a non-White defendant against a White victim, may be perceived as the most dangerous and therefore the most deserving of severe punishment, including the death penalty (see Jennings, Richards, Smith, Bjerregaard, \& Fogel, 2014).

The limited research on death penalty cases involving domestic offender-victim relationships has left significant gaps in our knowledge as to the sentencing decisions of juries in cases of domestic homicides that are tried capitally versus capital homicides including other offender-victim relationships. In particular, although Rapaport's (1996) seminal piece on the domestic discount focused on capital cases, the question remains as to whether a domestic discount actually exists in jury decisions involving the death penalty. In addition, it is unclear whether there are particular legal and/or extralegal factors associated with sentencing domestic homicides compared with those that shape jury decisions in cases involving other offender-victim relationships. Given the prevalence of domestic homicides that occur each year, and the relatively few that are deemed "death eligible," domestic homicides that are tried capitally represent a novel and important population of death penalty cases that deserve a more focused inquiry. 


\section{Current Study}

Prior studies have provided limited, but generally supportive, evidence regarding a domestic discount in the criminal prosecution and sentencing of domestic homicides generally, and capital sentencing specifically. However, only one study to date has quantitatively examined the case characteristics of domestic homicides that have merited capital punishment, and that study is limited by its small sample and focus on cases tried under the jurisdiction of the U.S. Armed Forces capital punishment system. Addressing this dearth of research, the present study uses a large sample of capital cases from North Carolina to both extend and expand our knowledge regarding death penalty decision making involving domestic offenders and victims. This is accomplished through the examination of (a) whether the domestic offender-victim relationship is significantly associated with lower odds of death sentencing than cases with other offender-victim relationships, and (b) whether the domestic victim-offender relationship (as well as other offender-victim relationship) moderates the effect of legal and extralegal case characteristics on jury assessment of the death penalty. Further, the impact of individual aggravators and mitigators on jury decision making are explored across the three models.

It should be stressed that the research questions we pursue here relate specifically to jury decisions in capital murder trials. In doing so, we make no attempt to account for prior decisionmaking processes in the criminal justice system, that is, prosecutorial discretion in selecting cases for first-degree murder charges and opting to pursue the death penalty (Baldus \& Woodworth, 2003). Nevertheless, the trial-level decisions of juries analyzed here are arguably the most crucial part of the capital punishment process and most subject to the influence of a wide range of factors impacting the collective decision of a jury to impose a death sentence. It is therefore a particularly relevant level at which to evaluate whether the death penalty is assessed in a differential fashion in cases involving domestic offender-victim relationships.

\section{Method}

\section{Data and Sample}

The data for this research were taken from the North Carolina Capital Sentencing Project (NCCSP; see Kavanaugh-Earl et al., 2008, for a full description). The NCCSP consists of information derived from a population of jury decisions in the penalty phase of capital murder trials in North Carolina during the period 1977-2009 $(N=1,356)$. The initial date marks the return to capital punishment in North Carolina following the Furman v. Georgia (1972) decision that suspended its use, and the Gregg v. Georgia (1976) decision that allowed its resumption. The latter date is the last year for which a full contingency of information is available. To reemphasize, our focus is on jury decisions regarding the death penalty because it is arguably the most important phase of the capital punishment process in actually determining who receives a death sentence. Also, because capital murder sentencing decisions are subject to a host of dynamics that may influence the group decision-making process required of juries, it is a particularly instructive level at which to determine whether offender-victim relationships, especially those found in domestic murders, tend to be viewed, and therefore responded to, differently than other types of murders for which the death penalty is sought.

For purposes of the multivariate analyses reported here, it was necessary to use a subset of the NCCSP data because the U.S. Supreme Court decision McKoy v. North Carolina (1990) altered the manner in which the presentation of mitigating circumstances, a crucial legal feature of the sentencing phase of capital murder trials in North Carolina, is responded to by the jury. Prior to McKoy, jurors had to be unanimous in their acceptance of a mitigator for it to be recorded as accepted on the "Issues and Recommendation as to Punishment" form that capital juries in North Carolina have to complete. Following the McKoy decision, unanimity in acceptance of mitigators is not required; they are recorded as accepted even if only a single juror indicates during deliberations that he or she accepts it. (See Kremling et al. [2007] for an extensive discussion and analysis of the impact of McKoy on jury deliberations in North Carolina capital murder trials.) Consequently, the impact of mitigation in cases before and after the McKoy decision must be analyzed separately.

The working data set for this study consists of a population of all 935 cases tried during the time period from April 1990 to December 2009 (hereafter, "post-McKoy"). Of these, 800 contained information for analyses containing the extensive set of control variables that are utilized in this study. Reasons for the loss of post-McKoy cases are as follows: (a) following extensive analyses, 31 cases were removed because they included female defendants, resulting in cell counts that were determined too small to reliably assess the effects of defendant sex across the offender-victim relationship models; (b) when including mitigation as a control variable, 48 cases were lost because the jury did not find an aggravating circumstance and therefore did not consider mitigation; (c) there were 10 instances in which, despite jury instructions, the "Issues and Recommendation as to Punishment" form was found to be blank, rendering those cases absent of any information concerning jury responses to aggravation or mitigation (if a jury does not issue a recommendation, the default is an automatic sentence of life imprisonment); (d) 20 cases did not have an "Issues and Recommendation as to Punishment" form in either appeals files or original county files, most likely because they were not completed by the jury; (e) 20 cases fell into a category of cases dubbed "hybrid," in which a sentencing hearing was conducted, but the jury was posed a question on the "Issues and Recommendation as to Punishment" form as to whether the crime deserved the death penalty - if answering "no," deliberations ceased and the defendant was assigned a death penalty; (f) there were four cases in which the marital status of the victim, a control variable used in the analyses, could not be determined; and ( $\mathrm{g}$ ) two cases had missing data on one or more of the control variables. It should be noted that all of these missing cases except one were those in which the defendant was assessed a life sentence, leading to a slight overrepresentation of death sentences in the reduced data set $(49 \%)$ compared with the overall post-McKoy data (43.2\%). Additionally, compared with the full "post-McKoy" data set, the relative proportion of domestic cases is virtually 
identical to those found in the reduced data set: $21.2 \%$ (full post-McKoy) versus $20.1 \%$ (reduced data set).

\section{Measures}

The sentencing phase of North Carolina capital murder trials. Because a number of the variables made available by NCCSP derive from the sentencing phases of trials in the data set, it is useful to briefly provide an overview of those proceedings. The sentencing phase of North Carolina capital murder trials is structured around presentation of aggravating circumstances by the prosecution and mitigating factors by the defense. Prosecutors must prove that one or more of 11 statutory aggravating factors existed in the circumstances surrounding the crime (North Carolina General Statutes, n.d.). Following that presentation, the defense can present any of nine statutory mitigating circumstances on behalf of the defendant, as well as an unlimited number of nonstatutory mitigating factors as long as they have received prior approval from the trial judge (North Carolina General Statutes, n.d.). Jurors are asked to indicate their acceptance or rejection of each aggravator and mitigator presented on an "Issues and Recommendation as to Punishment" form, and then they are asked to weigh the impact of aggravation versus mitigation in rendering a recommendation for a sentence of death or life in prison that is recorded on the form. Although termed a "recommendation," the jury's sentence is binding, pending the outcome of subsequent judicial appeals. As a note, the number of aggravating circumstances accepted by the jury in the working data set ranged from 0 to 9 , whereas the number of mitigators accepted varied from 0 to 111.

Dependent variable. Capital jurors in North Carolina are afforded only two sentencing options: (a) life in prison without the possibility of parole, or (b) the death penalty. Therefore, the dependent variable, jury recommendation, is expressed dichotomously $(0=$ life without parole, $1=$ death penalty $)$.

\section{Independent variables.}

Offender-victim relationship. The majority of previous research has relied on dichotomous groups of intimate partners and nonintimate partners; however, Black's relational distance hypothesis, as well as previous research by Dawson (2004), provides evidence that this dichotomy may be overly simplistic and mask important differences, stemming from the fact that intimacy exists on a spectrum. However, the desire for specificity regarding offender-victim relationship must be balanced with methodological considerations such as group sample size(s) and statistical power. Given that Dawson did find evidence that differences exist regarding sentencing across intimates, family members, and strangers, but not friends or acquaintances, we attempted to balance both theoretical and methodological considerations in our analysis. Specifically, given the small number of intimate partner and other family member cases, we developed a three-group categorization regarding offender-victim intimacy: domestics ( $n=$ 161 ), other known (friends/acquaintances; $n=359$ ), and strangers $(n=280)$. We also analyzed intimate partners versus other domestic cases in the final model.

Control variables. Additional independent variables for the analysis were selected to include factors frequently selected as target and control variables in the death penalty literature (Baldus \& Woodworth, 2003; Baldus, Woodworth, Zuckerman, Weiner, \&
Gross, 2009), divided into what could generally be termed extralegal and legal factors of the cases. Extralegal characteristicsfactors that, in a judicial sense, should not be related to sentencing decisions - comprised both victim and defendant characteristics, including victim age (under 18 years old, over 60 years old, and age 18 to 59 as the reference category) and marital status (married/ widowed $=1$, single/divorced $=0$ ), as well as whether the defendant was 25 years or younger (yes $=1$, no $=0$ ). In addition, in line with prior death penalty research using North Carolina data by Unah (2011), two racial dyad variables were included, nonWhite-defendant/non-White-victim (yes $=1$, no $=0$ ) and nonWhite-defendant/White-victim (yes $=1$, no $=0$ ). The reference category was collapsed to include all White defendant cases $(n=$ $276)$, because of the small number of cases involving Whitedefendants/non-White-victims $(n=41)$. Also, for both victims and offenders, the non-White category in this data is heavily dominated by Blacks, but also includes American Indians, Asians, Blacks, and Hispanics. Further, because of the potential impact on juror's perception of the victim, we included whether the victim was involved in or associated with illegal activity at the time of the murder (yes $=1$, no $=0$ ). Also included in the extralegal category was whether the trial occurred in an urban jurisdiction (yes $=1$, no $=0)^{1}$ and whether the defendant was represented by a private attorney at trial (yes $=1$, no $=0$ ).

Legal control variables, consisting of aspects of the case that juries are explicitly called upon to take into account in reaching their sentencing decisions, included the total number of aggravators accepted by the jury as well as the total number of mitigators accepted by the jury. To capture more nuanced elements shown in previous studies to have an impact on jury decisions, we also control for whether the jury accepted as an aggravating circumstance that there was more than one victim murdered (yes $=1$, no $=0)$, whether victim rape prior to the murder was accepted as an aggravator (yes $=1$, no $=0$ ), whether the jury accepted the aggravating circumstance that the murder was heinous and cruel (yes $=1$, no $=0$ ), and whether the jury accepted the mitigator that the defendant had no prior criminal record for (yes $=1$, no $=0$ ).

\section{Results}

In Table 1 (Columns 1 to 4), legal and extralegal characteristics and significance tests for each of the three offender-victim relationship categories - domestics, other known (friends/acquaintances), and strangers - are presented. In addition, Column 4 presents the characteristics for cases including intimate partner offender-victims. Findings demonstrate that there are no significant bivariate differences regarding juror death penalty decision making among the three offender-victim relationship categories; juries decide in favor of death in $50 \%, 49 \%$, and $48 \%$ of the cases, respectively. However, significant bivariate differences were demonstrated on six of the extralegal characteristics and three of the

${ }^{1}$ The 15 North Carolina counties classified by the N.C. Rural Economic Development Center, Inc. (2013) as "urban" (more than 250 people per square mile in density) include Alamance, Buncombe, Cabarrus, Catawba, Cumberland, Davidson, Durham, Forsyth, Gaston, New York: Guilford Press, Mecklenburg, New Hanover, Orange, Rowan, and Wake. This definition and its rural counterpart are incorporated into North Carolina legislation. 
Table 1

Characteristics of Variables Used in Multivariate Analysis, With Percent of Cases for Each Variable by Offender-Victim Relationship Category

\begin{tabular}{|c|c|c|c|c|c|}
\hline & \multicolumn{3}{|c|}{$n(\%)$} & \multirow[b]{2}{*}{$\chi^{2} / F$} & \multirow[b]{2}{*}{$\begin{array}{l}\text { Intimate partner } \\
\text { cases }(n=86)\end{array}$} \\
\hline & $\begin{array}{l}\text { Domestic cases } \\
\quad(n=161)\end{array}$ & $\begin{array}{l}\text { Other known cases } \\
\qquad(n=359)\end{array}$ & $\begin{array}{l}\text { Stranger cases } \\
\quad(n=280)\end{array}$ & & \\
\hline Juror decision of death penalty & $81(50 \%)$ & $176(49 \%)$ & $135(48 \%)$ & 0.18 & $41(48 \%)$ \\
\hline Non-White defendant and White victim & $7(4 \%)$ & $67(19 \%)$ & $117(42 \%)$ & $88.57^{* * * *}$ & $5(6 \%)$ \\
\hline Non-White defendant and non-White victim & $79(49 \%)$ & $149(42 \%)$ & $64(23 \%)$ & $37.34^{* * * *}$ & $47(55 \%)$ \\
\hline Victim female & $131(81 \%)$ & $114(32 \%)$ & $104(37 \%)$ & $118.60^{* * * *}$ & $85(99 \%)$ \\
\hline Child victim (17 years or younger) & $27(17 \%)$ & $42(12 \%)$ & $30(11 \%)$ & 3.73 & $7(8 \%)$ \\
\hline Older victim (60 years or older) & $27(17 \%)$ & $70(19 \%)$ & $59(21 \%)$ & 1.21 & $2(2 \%)$ \\
\hline Victim married/widowed & $89(55 \%)$ & $125(35 \%)$ & $143(51 \%)$ & $26.08^{* * * *}$ & $45(52 \%)$ \\
\hline Victim illegal activity & $6(4 \%)$ & $97(27 \%)$ & $43(15 \%)$ & $42.84^{* * * * *}$ & $4(5 \%)$ \\
\hline Defendant 25 years or younger & $36(22 \%)$ & $156(43 \%)$ & $193(69 \%)$ & $94.49^{* * *}$ & $12(14 \%)$ \\
\hline Urban jurisdiction & $66(41 \%)$ & $171(48 \%)$ & $144(51 \%)$ & 4.62 & $35(41 \%)$ \\
\hline Total aggravators accepted & $1-6 ; M=1.81$ & $1-8 ; M=2.21$ & $1-9 ; M=2.38$ & $11.26^{* * * *}$ & $1-6 ; M=1.72$ \\
\hline Total mitigators accepted & $0-41 ; M=12.31$ & $0-111 ; M=12.01$ & $0-50 ; M=12.89$ & 0.55 & $0-38 ; M=12.80$ \\
\hline Total number of victims killed & $1-3 ; M=1.39$ & $0-9 ; M=1.61$ & $1-9 ; M=1.73$ & $5.00^{* * *}$ & $1-2 ; M=1.21$ \\
\hline Defendant no prior record & $60(37 \%)$ & $115(32 \%)$ & $98(35 \%)$ & 1.50 & $29(34 \%)$ \\
\hline Victim rape & $6(4 \%)$ & $35(10 \%)$ & $28(10 \%)$ & $6.15^{*}$ & $2(2 \%)$ \\
\hline Heinous and cruel & $70(43 \%)$ & $113(31 \%)$ & $75(27 \%)$ & $13.22^{* * *}$ & $35(41 \%)$ \\
\hline Private attorney & $8(5 \%)$ & $19(5 \%)$ & $5(2 \%)$ & 5.53 & $6(5 \%)$ \\
\hline
\end{tabular}

Note. Domestic cases include family members such as parents, siblings, and children, as well as current and/or former sexual/romantic partners (i.e., boyfriends, girlfriends, spouses). Other known cases include friends and acquaintances. Stranger cases include victims and offenders who were unknown to each other. $\chi^{2} / F$ test presents statistical differences for each variable across offender-victim relationship. The additional column for Intimate Partner cases presents the number and percent of cases including current and/or former sexual/romantic partners (i.e., boyfriends, girlfriends, spouses).

${ }^{*} p<.05 .^{* * *} p<.01 .^{* * * *} p \leq .001$

legal characteristics across the victim-offender relationship categories.

We next estimated a logistic regression analysis to examine whether there is a relationship between the offender-victim relationship categories and juror death penalty decision making, while controlling for the previously described legal and extralegal case characteristics. Logistic regression analysis allows researchers to calculate the percent change in odds for a given outcome (e.g., receiving the death penalty) for each variable included in the model (e.g., victim sex, race), while simultaneously controlling for the other relevant factors in the model. Percent change in odds was calculated by subtracting 1 from the exponentiated coefficient $(B)$ and then multiplying this number by 100 . Specifically, we regressed the influence of domestic-offenders/victims and other-known-offenders/victims (compared with stranger-offenders/ victims) on the likelihood that a jury would choose death versus life without parole. Findings from this analysis are presented in Table 2.

The results shown in Table 2 demonstrate no significant association between domestic offender-victim cases and/or other known offender-victim cases compared with stranger offendervictim cases and jury decision making. Instead, four extralegal variables and five legal variables were associated with jury decision making. Specifically, non-White-defendant/non-White-victim cases, defendant (young) age, victim (older) age, and prosecution in an urban jurisdiction were significantly associated with a reduction in the likelihood of receiving the death penalty. Additionally, increased numbers of aggravators and the jury's acceptance that the case was heinous and cruel were associated with an increase in the odds of death, whereas higher numbers of mitigators, no prior record (for the defendant), and the use of a private attorney were all associated with a decrease in the likelihood of receiving death versus life without parole.

Although the present results provide evidence that there is no direct effect of domestic-offenders/victims (or other-known-offenders/victims or stranger-offenders/victims) on juror capitalsentence decision making in this sample of cases, it is unknown whether different predictors of jury death penalty decision making are in operation, given the offender-victim relationship, that is, whether the offender-victim relationship moderates the relationship between extralegal and legal variables and jury death-penalty sentencing. Consequently, we estimated a series of relationshipspecific logistic regression analyses to examine whether domesticoffenders/victims, other-known-offenders/victims, and strangeroffenders/victims moderate the effect of a myriad of legal and extralegal case characteristics on the odds that a jury will sentence a capital defendant to the death penalty versus life in prison.

Three logistic regression models examining any moderating effects on jury decision making for domestic offender-victim cases (including intimates and other family members), other known offender-victim cases (friends and casual acquaintances), and stranger offender-victim cases are presented in Table 3. Results from Model 1 in this table show that for domestic offender-victim cases, only two legal variables show statistically significant relationships with jury recommendations for the death penalty - the number of mitigators accepted by the jury, and whether the jury accepted the heinous and cruel aggravator. As shown in the domestic offender-victims model, each mitigating factor accepted is associated with a $10 \%$ decrease in the likelihood of receiving the death penalty, whereas a jury accepting heinous and cruel as an aggravator was associated with a $430 \%$ increase in the likelihood 
Table 2

Logistic Regression Predicting Death Penalty Controlling for Offender-Victim Relationship

\begin{tabular}{lrcccr}
\hline \multicolumn{1}{c}{ Variable } & \multicolumn{1}{c}{ B } & SE & OR & $95 \%$ CI & $\begin{array}{r}\text { Wald } \\
\text { statistic }\end{array}$ \\
\hline Other-known-victim/offenders & -0.02 & 0.21 & 0.99 & {$[0.65,1.49]$} & 0.01 \\
Domestic-victim/offenders & -0.06 & 0.29 & 0.94 & {$[0.53,1.66]$} & 0.05 \\
Non-White defendant and White victim & -0.12 & 0.24 & 0.89 & {$[0.56,1.41]$} & 0.26 \\
Non-White defendant and non-White victim & -0.51 & 0.21 & $0.60^{* *}$ & {$[0.40,0.90]$} & 6.11 \\
Victim female & 0.26 & 0.20 & 1.29 & {$[0.86,1.93]$} & 1.57 \\
Child victim & 0.22 & 0.28 & 1.25 & {$[0.72,2.17]$} & 0.62 \\
Older victim & -0.51 & 0.25 & $0.60^{*}$ & {$[0.37,0.97]$} & 4.29 \\
Victim married & -0.18 & 0.21 & 0.37 & {$[0.56,1.24]$} & 0.80 \\
Victim illegal activity & -0.44 & 0.24 & 0.07 & {$[0.40,1.04]$} & 3.26 \\
Defendant 25 or younger & -0.62 & 0.19 & $0.54^{* * * *}$ & {$[0.37,0.78]$} & 10.85 \\
Urban jurisdiction & -0.40 & 0.18 & $0.67^{*}$ & {$[0.47,0.95]$} & 5.10 \\
Total aggravators accepted & 0.48 & 0.09 & $1.61^{* * * * *}$ & {$[1.34,1.93]$} & 27.36 \\
Total mitigators accepted & -0.09 & 0.01 & $0.91^{* * * *}$ & {$[0.89,0.93]$} & 63.91 \\
Total number of victims killed & 0.15 & 0.10 & 1.16 & {$[0.95,1.41]$} & 2.12 \\
Defendant no prior record & -0.60 & 0.19 & $0.55^{* * *}$ & {$[0.38,0.80]$} & 10.02 \\
Victim rape & 0.52 & 0.37 & 1.68 & {$[0.81,3.48]$} & 1.95 \\
Heinous and cruel & 0.91 & 0.21 & $2.48^{* * * *}$ & {$[1.64,3.74]$} & 18.49 \\
Private attorney & -1.29 & 0.48 & $0.28^{* *}$ & {$[0.11,0.71]$} & 7.10 \\
\hline
\end{tabular}

Note. Domestic cases include family members such as parents, siblings, and children, as well as current and/or former sexual/romantic partners (i.e., boyfriends, girlfriends, spouses). Other known cases include friends and acquaintances. Stranger cases include victims and offenders who were unknown to each other. Stranger cases serve as the reference category.

${ }^{*} p<.05 .{ }^{* *} p<.01 .{ }^{* * * *} p \leq .001$.

of a death sentence, even when controlling for all the other variables in the model.

The results from Model 2 reveal that a mixture of legal and extralegal variables is associated with jury decisions to recommend the death penalty in cases including offenders and victims categorized as acquaintances or friends. Variables that were statistically significant predictors that increased the likelihood of juries' recommendations for the death penalty included higher numbers of accepted aggravators and acceptance by the jury that the case was heinous and cruel. Comparatively, victim illegal activity, higher numbers of accepted mitigators, no prior criminal record for the defendant, and whether the case was represented by a private attorney were all associated with a decreased likelihood of a jury recommending the death penalty in cases in which the offender and victim were acquaintances or friends.

Findings from Model 3 indicate that jury decision making regarding cases involving strangers was also significantly impacted by a range of both legal and extralegal variables. Among cases involving offenders and victims who were strangers, the defendant's age, case prosecution in an urban jurisdiction, higher numbers of aggravators, and the jury's acceptance of heinous and cruel as an aggravator were associated with a statistically significant increase in the likelihood that a jury would recommend the death penalty. Further, stranger cases with higher numbers of mitigators and/or cases including non-White defendants and nonWhite victims (compared with stranger cases with White-defendants/ White-victims or White-defendants/non-White-victims) were associated with a decreased likelihood of receiving the death penalty.

Given the differences in predictors for cases with domesticoffenders/victims compared with both cases involving otherknown-offenders/victims and stranger-offenders/victims, an additional analysis of the domestic cases that designates intimate partner cases as a control variable was estimated. The results of this additional analysis are presented in Table 4. Similar to the domestic model shown in Table 3, only the number of mitigators accepted, and acceptance of heinous and cruel as an aggravator, were statistically significant predictors of death sentencing. Specifically, higher numbers of mitigators were significantly related to a decrease in the odds that a jury would recommend the death penalty, whereas higher numbers of aggravators were associated with an increase in the odds of a death penalty recommendation. Importantly for this analysis, cases involving intimate partners were not associated with significantly different odds of receiving the death penalty than those involving other family members, again lending no support that a domestic discount can be found among jury decisions in this sample of capital murder trials.

Variables that were statistically significant predictors of death sentence recommendations across the offender-victim relationship models - the number of aggravators, number of mitigators, and jury acceptance of the heinous and cruel aggravator-were further examined using $z$ tests. $Z$ tests allow for a comparison of statistically significant coefficients across different samples (domestic offender-victim cases, other known offender-victim cases, and stranger offender-victim cases) using a standardized score (i.e., $z$ score) to determine which coefficients are the most robust predictors of the outcome. In other words, $z$ tests allow us to present interaction effects between the significant coefficients and victimoffender relationship in predicting death sentence recommendations in a simplified way that is easy to interpret. $Z$ scores were calculated for the coefficients across Models 1 through 3 (see Table 3) and are presented in Table 5. The $z$ formula used here is widely used in the criminological literature and is consistent with that used by Paternoster, Brame, Mazerolle, and Piquero (1998; see also Brame, Paternoster, Mazerolle, \& Piquero, 1998): 
RICHARDS, SMITH, FOGEL, AND BJERREGAARD

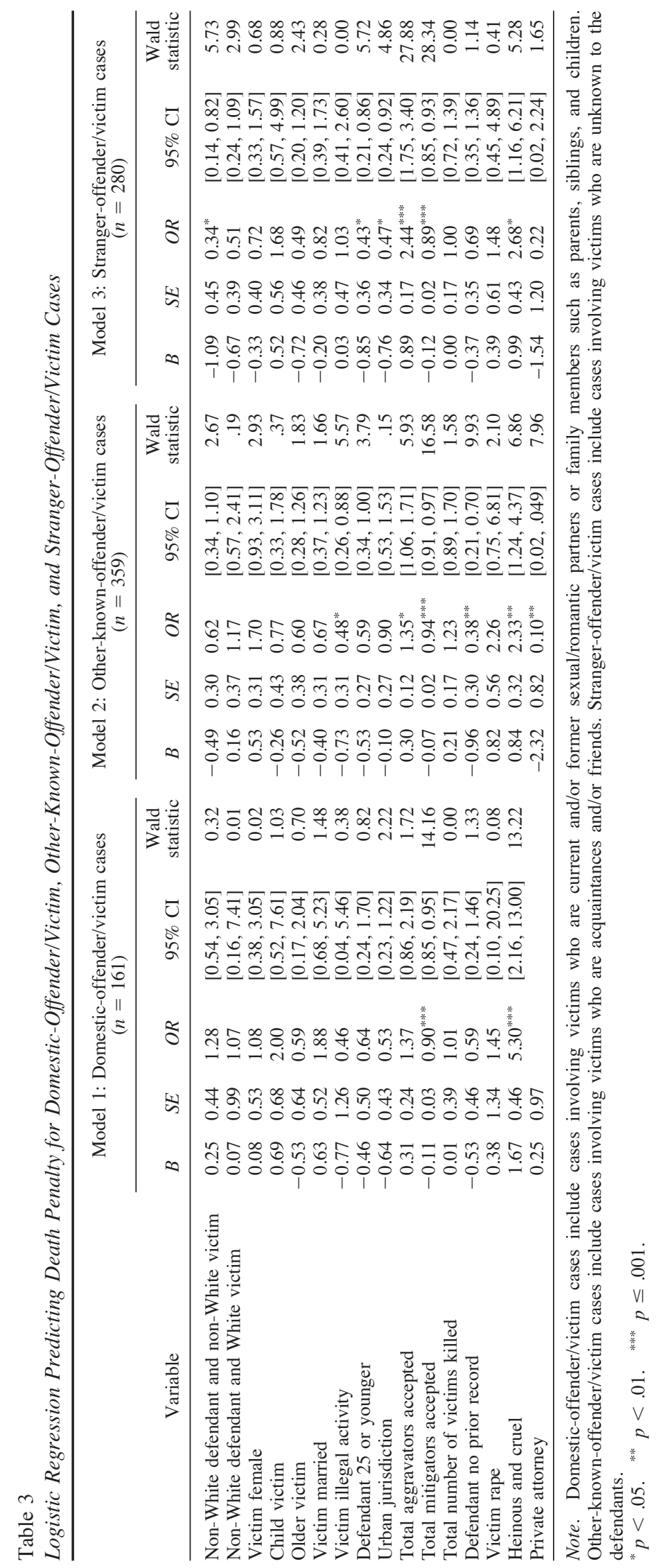


Table 4

Logistic Regression Predicting Death Penalty Controlling for Intimate Partner Cases Within Domestic Cases

\begin{tabular}{|c|c|c|c|c|c|}
\hline Variable & $B$ & $S E$ & $O R$ & $95 \% \mathrm{CI}$ & $\begin{array}{l}\text { Wald } \\
\text { statistic }\end{array}$ \\
\hline Non-White defendant and non-White victim & 0.29 & 0.45 & 1.34 & {$[0.56,3.22]$} & 0.03 \\
\hline Non-White defendant and White victim & 0.17 & 0.99 & 1.18 & {$[0.17,8.19]$} & 0.43 \\
\hline Victim female & 0.31 & 0.59 & 1.37 & {$[0.43,4.35]$} & 0.28 \\
\hline Child victim & 0.54 & 0.71 & 1.72 & {$[0.43,6.90]$} & 0.59 \\
\hline Older victim & -0.78 & 0.70 & 0.46 & {$[0.12,1.79]$} & 1.26 \\
\hline Victim married & 0.63 & 0.52 & 1.88 & {$[0.66,5.23]$} & 1.46 \\
\hline Victim illegal activity & -0.66 & 1.26 & 0.52 & {$[0.04,6.11]$} & 0.28 \\
\hline Defendant 25 or younger & -0.58 & 0.53 & 0.56 & {$[0.20,1.58]$} & 1.19 \\
\hline Urban jurisdiction & -0.69 & 0.43 & 0.50 & {$[0.22,1.17]$} & 2.53 \\
\hline Total aggravators accepted & 0.34 & 0.24 & 1.40 & {$[0.87,2.24]$} & 1.92 \\
\hline Total mitigators accepted & -0.11 & 0.03 & $0.90^{* * * *}$ & {$[0.85,0.95]$} & 13.66 \\
\hline Total number of victims killed & -0.09 & 0.41 & 0.92 & {$[0.41,2.04]$} & 0.05 \\
\hline Defendant no prior record & -0.53 & 0.46 & 0.59 & {$[0.24,1.46]$} & 1.30 \\
\hline Victim rape & 0.26 & 1.41 & 1.30 & {$[0.08,20.46]$} & 0.28 \\
\hline Heinous and cruel & 1.64 & 0.46 & $5.17^{* * * *}$ & {$[2.10,12.75]$} & 0.04 \\
\hline Private attorney & 0.24 & 0.97 & 1.27 & {$[0.19,8.50]$} & 12.73 \\
\hline Intimate partner & -0.51 & 0.58 & 0.60 & {$[0.19,1.87]$} & 0.06 \\
\hline
\end{tabular}

Note. Domestic cases include family members such as parents, siblings, and children, as well as current and/or former sexual/romantic partners (i.e., boyfriends, girlfriends, spouses). Intimate partner cases include current and/or former sexual/romantic partners (i.e., boyfriends, girlfriends, spouses).

**** $p \leq .001$.

$$
z=\frac{b_{1}-b_{2}}{\sqrt{S E b_{1}^{2}+S E b_{2}^{2}}}
$$

$Z$ scores for the number of aggravators accepted among friends or acquaintances (Model 2) and strangers (Model 3) attained statistical significance $(z=2.84 ; p<.01)$, indicating that case aggravation was a more robust predictor of receiving the death penalty in trials involving other-known-offenders/victims (i.e., friends or acquaintances, or trials including stranger-offenders/ victims). There were no differences observed across Models 1 through 3 for mitigation or for case designation as heinous and cruel.

Finally, in Table 6, the submission, acceptance, and impact of individual aggravators and mitigators noted in the prior studies on sentencing domestic homicides were examined for the domestic cases, and these results were compared with cases of friends or acquaintances and strangers. In domestic homicide cases, the heinous and cruel aggravator resulted in the highest rate of death sentences among the aggravators examined. Specifically, 85 cases $(53 \%)$ submitted evidence regarding heinousness, it was accepted in $82 \%$ of the submitted cases, and resulted in the death penalty
$75 \%$ of the time. To compare, heinous and cruel was submitted in $43 \%$ and $33 \%$ of cases including friends/acquaintances and strangers, respectively, and resulted in the death penalty $68 \%$ and $71 \%$ of the time. Further, the rape aggravator resulted in the death penalty among $67 \%$ of domestic cases accepting the presence of the rape aggravator; conversely, acceptance of the rape aggravator resulted in a death penalty rate of $83 \%$ and $75 \%$, respectively, for cases involving friends/acquaintances and strangers. For the domestics model similar rates of submission: $30 \%$ and $31 \%$, acceptance: $96 \%$ and $100 \%$, and associated death sentences: $61 \%$ and $54 \%$, were observed for the aggravators, "the murder was committed in the course of another felony," and "prior record of violence." A nearly identical pattern for these two aggravators was observed for cases involving friends/acquaintances and strangers. Finally, murder for pecuniary gain was submitted the least often in domestic cases compared with cases involving friends/acquaintances and strangers ( $12 \%$ vs. $26 \%$ and $37 \%$, respectively); however, when it was submitted in cases involving domestics, it was accepted $90 \%$ of the time and resulted in the death penalty in $44 \%$ of cases. Similar acceptance rates and death penalty rates were observed for cases involving friends/acquaintances and strangers.

Table 5

Z-Score Analysis Comparing Significant Variables From Multivariate Analysis Across Domestic-Offender/Victim, Other-Known-Offender/Victim, and Stranger-Offender/Victim Cases

\begin{tabular}{|c|c|c|c|c|c|c|c|c|c|c|c|c|c|c|c|}
\hline \multirow[b]{2}{*}{ Variable } & \multicolumn{2}{|c|}{ Model 1} & \multicolumn{2}{|c|}{ Model 2} & \multirow[b]{2}{*}{$Z$} & \multicolumn{2}{|c|}{ Model 1} & \multicolumn{2}{|c|}{ Model 3} & \multirow[b]{2}{*}{$Z$} & \multicolumn{2}{|c|}{ Model 2} & \multicolumn{2}{|c|}{ Model 3} & \multirow[b]{2}{*}{$Z$} \\
\hline & $B$ & $S E$ & $B$ & $S E$ & & $B$ & $S E$ & $B$ & $S E$ & & $B$ & $S E$ & $B$ & $S E$ & \\
\hline Total aggravators & - & - & - & - & - & - & - & - & - & - & 0.30 & 0.12 & 0.89 & 0.17 & $-2.84^{* * *}$ \\
\hline Total mitigators & -0.11 & 0.03 & -0.07 & 0.02 & -1.11 & -0.11 & 0.03 & -0.12 & 0.02 & 1.77 & -0.07 & 0.02 & -0.12 & 0.02 & 0.28 \\
\hline Heinous and cruel & 1.67 & 0.46 & 0.84 & 0.32 & 1.48 & 1.67 & 0.46 & 0.99 & 0.43 & 1.08 & 0.84 & 0.32 & 0.99 & 0.43 & -0.28 \\
\hline
\end{tabular}

$$
\text { *** } p<.01 \text {. }
$$




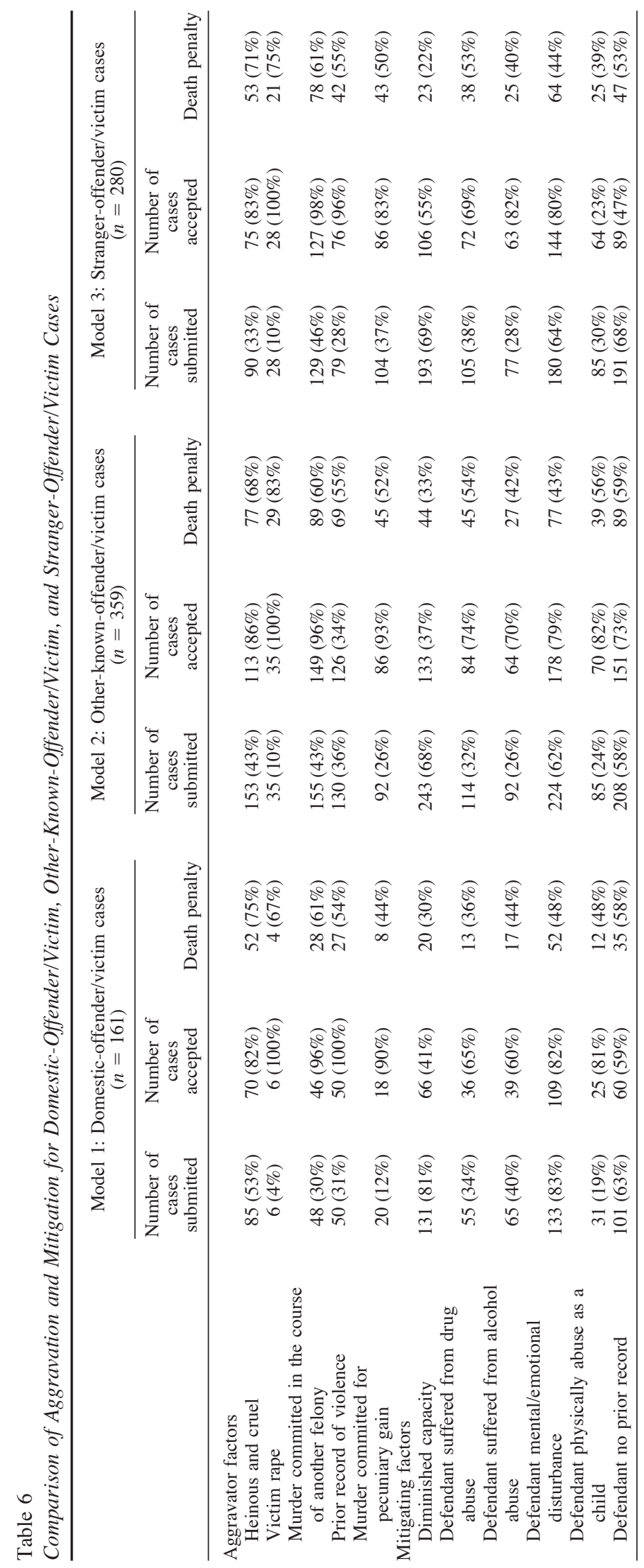


Turning to mitigators, domestic cases including the acceptance of the diminished capacity mitigator resulted in the death penalty the least often, $30 \%$ of the time, compared with the other mitigators examined. The diminished capacity mitigator was similarly effective in swaying the jury in favor of life without parole in cases involving friends/acquaintances, with a $33 \%$ death penalty rate, and more effective in cases involving strangers, in which cases including the diminished capacity mitigator resulted in the death penalty $22 \%$ of the time. "Defendant suffered from drug abuse" was the next most effective mitigator in domestic cases, with a death penalty rate of $36 \%$, compared with $54 \%$ among cases including friends/acquaintances and 53\% among cases involving strangers. In contrast, defendant alcohol use and/or emotional disturbance were least effective in domestic cases (44\% and $48 \%$ death penalty), compared with cases involving friends/acquaintances ( $42 \%$ and $43 \%)$ or strangers (40\% and $44 \%)$. Physical abuse of the defendant as a child was rarely submitted as a mitigator in domestic cases $(19 \%)$, but was accepted $81 \%$ of the time once submitted, and resulted in a death penalty rate of $48 \%$. Physical abuse of the defendant as a child was submitted more often among friends/acquaintances (24\%) and strangers (30\%), with corresponding acceptance rates of $82 \%$ and $23 \%$, and death rates upon acceptance of $56 \%$ and $39 \%$. Finally, patterns for submission, acceptance, and resulting death rates for "no defendant prior record" was similar across offender-victim relationships, with $58 \%$ of domestic cases, $59 \%$ of cases involving friends/acquaintances, and $53 \%$ of cases involving strangers resulting in the death penalty.

\section{Discussion and Conclusions}

As stated earlier, the purpose of this research was to (a) explore whether a "domestic discount" - the tendency toward less stringent sentencing, especially imposition of a death sentence-existed for capital murder cases with offenders and victims who had domestic relationships, and relatedly, (b) to determine whether different categories of offender-victim relationship impacted the effect of relevant case characteristics on death sentencing. Addressing the first question, our results found no compelling evidence for a domestic discount, either for domestic relationships, in general, or for intimate partner relationships (a focus of previous literature), more specifically, either at the bivariate or multivariate level. As our findings reveal, the percentages of death sentences for domestic cases are quite similar to other categories of offender-victim relationships. When deconstructed to isolate cases involving intimate partners, the percentage of death sentences recommended is $2 \%$ lower than that of all domestic cases, $1 \%$ lower than cases involving friends/acquaintances, and identical to that of cases involving strangers (48\%). Multivariate analysis further indicated the absence of a statistical relationship between each of the offender-victim relationship categories and juror sentencing decision making. Thus, despite the complexity presented by seeking the death penalty in cases involving offender-victim domestic relationships, juries overall seem neither more nor less inclined to impose the extreme sanction of recommending the death penalty.

The present findings call into question Rapaport's (1996) suggestion that a "domestic discount" is applied in capital sentencing cases. Of note, Rapaport supported this assertion using findings from a qualitative analysis of capital cases involving domestic partners only - no control group including nondomestic homicide cases and/or cases that were not sentenced to death was used. However, in our more comprehensive analysis estimating the relationship between offender-victim relationship and juror capital sentence decision making, while controlling for a number of potentially confounding variables and using a near-population of first-degree murder cases from over nearly three decades, we find no support for Rapaport's contention. Instead, our findings are more in line with the singular prior quantitative assessment of the domestic discount by Grosso et al. (2010), who also found no significant differences in the likelihood of receiving the death penalty for domestic homicide cases and nondomestic homicide cases sentenced in military court. Taken together, these findings suggest a need for further research to examine whether a domestic discount in capital sentencing decision making may hold in jurisdictions other than the state of North Carolina and the United States military courts.

Turning to the second research issue pursued here, our findings reveal substantial differences in predictors of sentencing across the offender-victim relationship models (see especially Table 3). Although it might be expected that domestic cases would present juries charged with determining whether or not to assess the death penalty with a particularly complex sets of dynamics, the domestic model proved to have the smallest set of statistically significant predictors, specifically, whether the jury found the murder to have involved cruel and heinous circumstances (resulting in an increase) and the number of mitigators accepted at trial (resulting in a decrease). No other variable in the model was shown to have a statistically significant relationship with jury decision making, including any of the extralegal variables that have been the objects of so much of the death penalty research literature. The domestic cases, in effect, were the most "legalistic" of the three models in its pattern of predictors.

Thus, we do not suggest that cases involving domestic-offenders/victims are the same as cases involving friends/acquaintances or strangers, but instead we submit that differences stem from the case characteristics present in domestic cases, especially individual mitigators and aggravators, and it is their corresponding impact on the jury, rather than any inherent differential treatment based on offender-victim relationship alone, that effects jury decision making. Specifically, the finding of a narrow range of predictors was undoubtedly influenced by domestic cases typically having few aggravating circumstances that meet statutory definitions by which prosecutors can pursue capital punishment. Indeed, in the large sample of death penalty trials in North Carolina from 1991 to 2009 utilized here, domestic cases had an average of 1.81 aggravating factors accepted at trial, compared with an average of 2.21 for cases involving friends/acquaintances and 2.38 for cases involving strangers. Among the aggravating circumstances available, designating the case as cruel and heinous entails a degree of subjectivity that ultimately rests on the jury's judgment, assuming that it meets minimal judicial standards to allow for its introduction as an aggravator. If accepted, the cruel and heinous aggravator appears to have a powerful effect on the jury's view of the case, a finding consistent with the extant literature examining the effect of this aggravator (Bowers, 1995; Luginbuhl \& Howe, 1995). In our data set, among domestic cases in which "cruel and heinous" was accepted as an aggravating factor, the death penalty was recom- 
mended in $75 \%$ of those cases. Similarly, Rapaport's (1996) research indicated that in $48 \%$ of cases of males on death row for domestic homicide, the jury had accepted extreme brutality as an aggravating factor.

On the other hand, the path for avoidance of the death penalty among domestic cases appears to lie in an effective presentation of mitigation by the defense, although the average number of mitigators accepted did not significantly vary by offender-victim relationship, leading us to an examination of mitigators that may have had notable influences. By far, the most common mitigator submitted in domestic cases was that the defendant engaged in the crime under a condition of mental or emotional disturbance. This factor was submitted in $83 \%(n=133)$ of domestic cases and was accepted $82 \%$ of the time. If accepted, the death penalty was assessed in $48 \%$ of the cases.

The next most frequently submitted mitigating circumstance was thematically similar in arguing that the defendant had a diminished capacity to appreciate the criminality of his or her conduct, and is frequently used to argue the impact of the defendant's substance use or abuse in contributing to the murder. The work of Bjerregaard et al. (2010) provides a caution regarding this strategy by defense teams. Their findings suggest that mitigation involving alcohol use or abuse can be successful in swaying the jury toward a life sentence, but that mitigation involving drug use or abuse, even if accepted by the jury, is associated with an increased risk of a death sentence. Here, we found that in domestic cases $36 \%$ of cases including the drug-abuse mitigator ended in the death penalty, compared with $54 \%$ and $53 \%$ of cases involving friend/acquaintances or strangers, respectively. Diminished capacity was the most effective mitigator in domestic cases - in cases in which diminished capacity was accepted, death was recommended in only $30 \%$ of the cases. In comparison, death was recommended in $48 \%$, respectively, of cases in which the defendant suffered from mental or emotional disturbance or was physically abused as a child, and $58 \%$ of cases in which the defendant had no prior record.

It may be speculated that success in convincing jurors to accept mitigators regarding a mental abnormality contributed to an impression that the crime was an aberrant action on the part of the defendant, one committed under conditions of extreme distress that related directly or indirectly to the dynamics of family relationships. Consequently, the defendant came to be viewed as not being among the "worst of the worst" offenders who deserve the death penalty. Compared with other types of offender-victim relationships, proving this to the satisfaction of the jury may be less challenging in cases involving family members or intimate partners, in which murders often occur in the context of complex, intense emotions. Although jurors may be repelled by the defendant's actions, an effective presentation of mitigation may elicit some degree of understanding as to what led to those actions (for summary discussions of the dynamics of mitigation, see Bowers, Brewer, \& Lanier, 2009; Haney, 2003). Further, although Rapaport (1996) does not discuss the presence of individual mitigators in her previous assessment of death penalty sentencing among domestic homicides, she does suggest that lower levels of blameworthiness and corresponding sentence severity associated with homicides resulting from heat of passion and/or diminished responsibility versus cold blood may disproportionately impact sentences for domestic homicides.
In contrast to domestic cases, cases involving friends/acquaintances or strangers had considerably more complex patterns of predictors that included a mixture of extralegal and legal variables. These included some factors that have been discussed at length in the existing literature, such as the impact of defendant-victim racial dyad. For example, consistent with Unah's (2011) research analyzing 5 years of homicides in North Carolina (see also Paternoster \& Brame, 2003), our results demonstrate a decreased likelihood of receiving the death penalty among non-White-defendant/ non-White-victim cases, but only for cases involving strangers. However, counter to extant research (e.g., Keil \& Vito, 1995; Paternoster \& Brame, 2008; Sorensen \& Wallace, 1995), no significant effect of non-White-defendant/White-victim cases was observed in any of the models. Although a large body of literature has addressed the topic of racial disparity in capital punishment (see Baldus, Woodworth, \& Pulaski, 1990, and Baldus et al., 2009, for a comprehensive overview), and disparity among certain racial dyads specifically (e.g., Keil \& Vito, 1990; Paternoster \& Brame, 2008; Sorensen \& Wallace, 1995; Unah, 2011), the current research is the first to deconstruct how this relationship is manifested on among cases differentiated on the basis of offender-victim relationships. It is important to note that only a small number of non-White-defendant/White-victim cases were observed among domestics.

Among legal factors, the influence of the cruel and heinous aggravator is evident across all three models, as is the number of mitigators accepted. In contrast to the domestic model, the total number of aggravators accepted is shown to have a statistically significant relationship with jury recommendations in the other two categories of offender-victim relationships, an effect that is particularly strong in cases in which offenders and victims are strangers as demonstrated by the significant $z$ score.

Although the present research provides a rigorous examination of the "domestic discount" in sentence decision making among a large population of capital murder trials, several limitations should be noted. As previously stated, the current study focuses on juror decision making, and as such, the findings provide information regarding the "domestic discount" at only one stage of the criminal justice system process. Because of the inherent challenges in trying domestic cases capitally (e.g., legal complexities, witness issues, family members testifying against one another), it is likely that prosecutors may utilize different criteria for choosing which domestic cases (vs. cases involving other known or stranger offendervictims) should be charged and prosecuted as first-degree murders, thus introducing a form of sample selection bias for sentencing research. In particular, prosecutors may be particularly circumspect in charging domestic cases capitally and may select only those for which the case is more clear-cut and, in effect, "winnable," thus narrowing the jury's decision to the legal factors involved in the case. Further research examining prosecutorial decision making in these types of cases would help better inform these issues and aid in determining whether the domestic discount is simply occurring at earlier stages in the process. Further, the small number of observations of some predictors (i.e., non-Whitedefendant/White-victim cases; victim illegal activity) among domestic cases may have suppressed effects that would be evident in a larger sample; however, given that this research uses a nearpopulation of capital cases over nearly three decades, we contend that the representation of such predictors in domestic cases accu- 
rately depicts their role in the capital jury decision-making process (i.e., they are rarely factors presented to capital juries when making sentencing decisions in domestic cases).

Additionally, we acknowledge that our data represent cases from a single state, North Carolina, and it is possible that divergent results may emerge, depending on the specific jurisdictions in which capital murder cases are being conducted. However, because of considerable variation in state legislation concerning the process governing the assessment of capital punishment (Snell, 2011), there is no national database by which analyses can be conducted. Consequently, analyses of death sentencing are necessarily restricted to single states, and have yielded substantial differences in research on similar topics (e.g., Barnett, 1985; Keil \& Vito, 1990, 1995; see also Stauffer et al., 2006; Williams \& Holcomb, 2004). Although recognizing this limitation to the broad generalizability of any results, it is noteworthy for the present study that North Carolina has been actively pursuing capital punishment since its reinstatement in state statutes in 1977, making it a state particularly relevant for discerning patterns associated with death sentencing. According to the most recently available comparative data (Death Penalty Information Center, 2014a), North Carolina ranked fourth in the cumulative number of death sentences returned $(n=443)$, ninth in the number of executions since $1976(n=43)$, and 19th in the number of executions per death sentence $(n=.097)$. As well, it is listed as having the sixth largest death row population $(n=160)$ in 2014 (Death Penalty Information Center, 2014b). In addition, and important for purposes of the research discussed here, there is ample publicly available documentation on capital murder trials in North Carolina that permit the reconstruction of data regarding some of the most important legal aspects of jury decision making presented here for replications in other states.

As a parting thought regarding the findings presented here, we find that the vast majority of capital punishment research has focused on the "big picture" of how this sanction functions in the criminal justice system of various U.S. states. For wholly appropriate reasons, much of the academic focus of death penalty research has been to decipher patterns of discrimination and inequity in its assessment. However, our research leads us to believe that there are a number of nuances in the operation of the death penalty in the United States that have not been fully explored. There are, in essence, other stories to be told that are embedded in subsets of capital murder cases, as the findings discussed here attest. Exploring these stories will ultimately contribute to a fuller understanding of capital punishment in the United States.

\section{References}

Auerhahn, K. (2007). Adjudication outcomes in intimate and non-intimate homicides. Homicide Studies: An Interdisciplinary \& International Journal, 11, 213-230. http://dx.doi.org/10.1177/1088767907304121

Baldus, D. C., \& Woodworth, G. (2003). Race discrimination and the death penalty: An empirical and legal overview. In J. R. Acker, R. M. Bohm, \& C. S. Lanier (Eds.), America's experience with capital punishment (2nd ed., pp. 501-551). Durham, NC: Carolina Academic Press.

Baldus, D. C., Woodworth, G., \& Pulaski, C. A., Jr. (1990). Equal justice and the death penalty: A legal and empirical analysis. Boston, MA: Northeastern University Press.
Baldus, D., Woodworth, G., Zuckerman, D., Weiner, N. A., \& Gross, C. M. (2009). Empirical studies of race and geographic discrimination in the administration of the death penalty: A primer on the key methodological issues. In C. S. Lanier, W. J. Bowers, \& J. R. Acker (Eds.), The future of America's death penalty (pp. 153-197). Durham, NC: Carolina Academic Press.

Barnett, A. (1985). Some distribution patterns of the Georgia death sentence. University of California Davis Law Review, 18, 1327-1374.

Bjerregaard, B., Smith, M. D., Fogel, S. J., \& Palacios, W. R. (2010). Alcohol and drug mitigation in capital murder trials: Implications for sentencing decisions. Justice Quarterly, 27, 517-537. http://dx.doi.org/ 10.1080/07418820903051623

Black, D. (1976). The behavior of law. New York, NY: Academic Press.

Bowers, W. J. (1995). The Capital Jury Project: Rationale, design, and preview of early findings. Indiana Law Journal (Indianapolis, IN), 70, 1043-1102.

Bowers, W. J., Brewer, T., \& Lanier, C. S. (2009). The capital jury experiment of the Supreme Court. In C. S. Lanier, W. J. Bowers, \& J. R. Acker (Eds.), The future of America's death penalty (pp. 199-221). Durham, NC: Carolina Academic Press.

Brame, R., Paternoster, R., Mazerolle, P., \& Piquero, A. (1998). Testing for the equality of maximum likelihood regression coefficients between two independent equations. Journal of Quantitative Criminology, 14, 245261. http://dx.doi.org/10.1023/A:1023030312801

Cooper, A., \& Smith, E. L. (2011). Homicide trends in the United States, 1980-2008, annual rates for 2009 and 2010 (NCJ 23608). Washington, DC: U. S. Department of Justice, Office of Justice Programs.

Dawson, M. (2004). Rethinking the boundaries of intimacy at the end of the century: The role of victim-defendant relationship in criminal justice decision-making over time. Law \& Society Review, 38, 105-138. http:// dx.doi.org/10.1111/j.0023-9216.2004.03801004.x

Dawson, M. (2012). Intimacy, homicide, and punishment: Examining court outcomes over three decades. Australian and New Zealand Journal of Criminology, 45, 400-422. http://dx.doi.org/10.1177/ 0004865812456850

Death Penalty Information Center. (2014a). Executions per death sentence. Retrieved from http://www.deathpenaltyinfo.org/executions-deathsentence

Death Penalty Information Center. (2014b). Death row inmates by state. Retrieved from http://www.deathpenaltyinfo.org/death-row-inmatesstate-and-size-death-row-year?scid $=9 \&$ did $=188 \#$ state

Furman v. Georgia, 408 U.S. 238 (1972).

Gillespie, L. K., Loughran, T. A., Smith, M. D., Fogel, S. J., \& Bjerregaard, B. (2014). Exploring the role of victim sex, victim conduct, and victimdefendant relationship in capital punishment sentencing. Homicide Studies: An Interdisciplinary \& International Journal, 18, 175-195. http:// dx.doi.org/10.1177/1088767913485747

Gregg v. Georgia, 428 U.S. 153 (1976).

Grosso, C. M., Baldus, D. C., \& Woodworth, G. (2010). The role of intimacy in the prosecution and sentencing of capital murder cases in the U.S. Armed Forces, 1984-2005. New Mexico Law Review, 40, 273-297.

Haney, C. (2003). Mitigation and the study of lives: On the roots of violent criminality and the nature of capital justice. In J. R. Acker, R. M. Bohm, \& C. S. Lanier (Eds.), America's experiment with capital punishment (2nd ed., pp. 469-500). Durham, NC: Carolina Academic Press.

Hessick, C. B. (2007). Violence between lovers, strangers, and friends. Washington University Law Review, 85, 343-407.

Holcomb, J. E., Williams, M. R., \& Demuth, S. (2004). White female victims and death penalty disparity research. Justice Quarterly, 21, 877-902. http://dx.doi.org/10.1080/07418820400096021

Jennings, W. G., Richards, T. N., Smith, M. D., Bjerregaard, B., \& Fogel, S. J. (2014). A critical examination of the "White victim effect" and death penalty decision-making from a propensity score matching ap- 
proach: The North Carolina experience. Journal of Criminal Justice, 42, 384-398. http://dx.doi.org/10.1016/j.jcrimjus.2014.05.004

Kavanaugh-Earl, J., Cochran, J. K., Smith, M. D., Fogel, S. J., \& Bjerregaard, B. (2008). Racial bias and the death penalty. In M. J. Lynch, E. B. Patterson, \& K. K. Childs (Eds.), Racial divide: Racial and ethnic biases in the criminal justice system (pp. 147-196). Monsey, NY: Criminal Justice Press.

Keil, T., \& Vito, G. (1990). Race and the death penalty in Kentucky murder trials: An analysis of post-Gregg outcomes. Justice Quarterly, 7, 189207. http://dx.doi.org/10.1080/07418829000090531

Keil, T., \& Vito, G. (1995). Race and the death penalty in Kentucky murder trials, 1976-1991: A study of racial bias in capital sentencing. American Journal of Criminal Justice, 20, 17-36. http://dx.doi.org/10.1007/ BF02886116

Kremling, J., Smith, M. D., Cochran, J. K., Bjerregaard, B., \& Fogel, S. J. (2007). The role of mitigating factors in capital sentencing before and after McKoy v. North Carolina. Justice Quarterly, 24, 357-381. http:// dx.doi.org/10.1080/07418820701485361

Luginbuhl, J., \& Howe, J. (1995). Discretion in capital sentencing instructions: Guided or misguided? Indiana Law Journal (Indianapolis, IN), 70, 1161-1181.

McKoy v. North Carolina, 494 U.S. 433 (1990).

Messing, J. T., \& Heeren, J. W. (2009). Gendered justice: Domestic homicide and the death penalty. Feminist Criminology, 4, 170-188. http://dx.doi.org/10.1177/1557085108327657

Miethe, T. D. (1987). Stereotypical conceptions and criminal processing: The case of the victim-offender relationship. Justice Quarterly, 4, 571-593. http://dx.doi.org/10.1080/07418828700089531

N.C. Rural Economic Development Center, Inc. (2013). Rural/urban counties in North Carolina. Retrieved from http://www.ncruralcenter.org/ index.php?option $=$ com_content $\&$ view $=$ article $\&$ id $=75 \&$ Itemid $=126$

North Carolina General Statutes. (n.d.) Subchapter XV. Capital punishment. Article 100. Retrieved from http://www.ncga.state.nc.us/ enactedlegislation/statutes/html/bysection/chapter_15a/gs_15a-2000 .html

Paternoster, R., \& Brame, R. (2003). An empirical analysis of Maryland's death sentencing system with respect to the influence of race and legal jurisdiction. Retrieved from http://www.aclu-md.org/ uploaded_files/0000/0376/md_death_penalty_race_study.pdf

Paternoster, R., \& Brame, R. (2008). Reassessing race disparities in Maryland capital cases. Criminology: An Interdisciplinary Journal, 46, 9711008. http://dx.doi.org/10.1111/j.1745-9125.2008.00132.x
Paternoster, R., Brame, R., Mazerolle, P., \& Piquero, A. (1998). Using the correct statistical test for the equality of regression coefficients. Criminology, 36, 859-866. http://dx.doi.org/10.1111/j.1745-9125.1998 .tb01268.x

Rapaport, E. (1991). The death penalty and gender discrimination. Law \& Society Review, 25, 367-384. http://dx.doi.org/10.2307/3053803

Rapaport, E. (1996). Capital murder, gender, and the domestic discount: A study of capital murder in the post-Furman era. SMU Law Review, 49, $1507-1548$

Richards, T. N., Jennings, W. G., Smith, M. D., Sellers, C. S., Fogel, S. J., \& Bjerregaard, B. (2014). Explaining the "female victim effect" in capital punishment: An examination of victim sex specific models of juror sentence decision-making. Crime and Delinquency. Advance online publication. http://dx.doi.org/10.1177/0011128714530826

Snell, T. L. (2011). Capital punishment, 2010 - Statistical tables (NCJ 236510). Washington, DC: U.S. Department of Justice.

Sorensen, J. R., \& Wallace, D. H. (1995). Capital punishment in Missouri: Examining the issue of racial disparity. Behavioral Sciences \& the Law, 13, 61-80. http://dx.doi.org/10.1002/bs1.2370130105

Stauffer, A. R., Smith, M. D., Cochran, J. K., Fogel, S. J., \& Bjerregaard, B. (2006). The interaction between victim race and gender on sentencing outcomes in capital murder trials. Homicide Studies: An Interdisciplinary \& International Journal, 10, 98-117. http://dx.doi.org/10.1177/ 1088767905285510

Unah, I. (2011). Empirical analysis of race and the process of capital punishment in North Carolina. Michigan State Law Review, 2011, 610 658.

Violence Policy Center. (2014). When men murder women: An analysis of 2012 homicide data. Retrieved from http://www.vpc.org/studies/ wmmw2014.pdf

Williams, M. R., \& Holcomb, J. E. (2004). The interactive effects of victim race and gender on death sentencing disparity findings. Homicide Studies: An Interdisciplinary \& International Journal, 8, 350-376. http://dx .doi.org/10.1177/1088767903262445 